\title{
LA IMPLANTACIÓN DE INTERNET EN LA GESTIÓN DE PERFILES PROFESIONALES EN INVESTIGACIÓN CIENTÍFICA
}

\author{
THE IMPLEMENTATION OF THE INTERNET IN THE MANAGEMENT OF \\ PROFESSIONAL PROFILES IN SCIENTIFIC RESEARCH
}

\author{
Sara Mandiá-Rubal \\ Universidade de Santiago de Compostela, Espanha \\ sara.mandia.rubal@gmail.com \\ Maricela López-Ornelas \\ Universidad Autónoma de Baja California (UABC), México \\ ornelas@uabc.edu.mx \\ José Miguel Túñez-López \\ Universidade de Santiago de Compostela (USC), Espanha \\ miguel.tunez@usc.es
}

RESUMEN: De los cambios observados en la comunicación de la ciencia, nuevos soportes; nuevas métricas; y nuevas tareas para un investigador que deberá ser proactivo digital en la difusión y promoción de sus trabajos; de donde emanan tres hipótesis de investigación $(H)$ : H1. Los investigadores españoles que publican en revistas de Comunicación indexadas en Scopus son proactivos digitales en redes sociales científicas; H2. Los investigadores con un mayor número de publicaciones son más proactivos digitales en redes sociales científicas; H3. Los investigadores más activos en redes sociales científicas tienen un Índice H más alto. Para la resolución de dichas hipótesis, y de los objetivos específicos relacionados, se emplean una metodología cuantitativa misma que puede ser replicada con las adaptaciones correspondientes, sin perder de vista, que el eje rector de la misma es la eficacia de ser visible en la Red. De una muestra de 2,257 autores se obtiene, en primer término, la verificación de las tres hipótesis señaladas; y en segundo, conclusiones derivadas de los objetivos específicos planteados. Algunas de esas conclusiones son: a) existen perfiles creados y conservados por incidencia directa de terceros; b) la tendencia al acceso abierto de la producción científica, se mantiene en alza en toda la secuencia temporal estudiada; c) ResearGate es la red de gestión de perfiles que más usuarios registra; d) dividida la muestra por géneros, la diferencia hombre/mujer no es significativa; e) las posibilidades de investigar y publicar son notablemente mayores para los profesionales del sector académico-universitario que para aquellos que provengan de cualquier otro entorno laboral.

PALABRAS CLAVE: Investigador tradicional; acceso abierto; evaluación científica; redes sociales para la gestión de perfiles profesionales; revistas científicas.

ABSTRACT: From all the observed changes in the communication of science, new supports, new metrics and new tasks for a researcher who must be a digitally proactive subject in the diffusion and advancement of their work; three research hypotheses emerge $(H): H 1:$ Spanish researchers who publish their articles in indexed communication journals 
in Scopus, are digitally proactive researchers in scientific social networks; $\mathrm{H}$ 2: Researchers with a high number of publications are more digitally proactive in scientific social networks; and H3: Active researchers in scientific social networks have a higher $\mathrm{H}$ index. To settle such hypotheses and the specific objectives related, a quantitative methodology is employed - the same that could be replicated with the corresponding adaptations, without overlooking, that its guiding principle is the efficiency of its visibility in the network. From a sample of 2.257 authors, it is possible to obtain; first, the verification of the three given hypotheses, and secondly, derived conclusions of the stated specific objectives. Some of the conclusions are: a) there is a direct incidence of third parties in the creation and preservation of profiles; b) the open access tendency of scientific research rose during the time of research; c) ResearchGate is the profile management network that has more registered users; d) when the sample is divided using the variable "gender", the difference between men and women is not significant; e) the possibilities of researching and publishing are notably higher for professionals in the academic sector than for those who belong to other work sectors.

KEYWORDS: Traditional researcher; open access; scientific assessment; social networks for the management of professional profiles; scientific journals.

\section{Introducción}

El origen y posicionamiento de Internet puede visualizarse como la principal metamorfosis en los procesos de la comunicación en red, incluso a cinco décadas de su aparición, seguimos siendo partícipes de las transformaciones en diversos contextos: socioculturales, políticos, económicos, académicos, tecnológicos y científicos (Castells, 2009).

Es evidente entonces, que el mundo de la comunicación científica ha renovado, ampliado, incrementado y diversificado las formas y métodos de acceso, consulta $y$ visibilidad de la ciencia. Cabe agregar, que el acceso abierto (AA [Open Access (OA]), es uno de ellos; mismo que corresponde a la necesidad de hacer visible la comunicación científica y extender el flujo e innovación del conocimiento.

Esta perspectiva expone una comunicación científica poliédrica, donde las estructuras del proceso de comunicación masiva en la Red, reorganizan, condicionan y complejizan los significados en una nueva era llamada Era de la información (CASTELLS, 2009). De tal forma, que la apertura del proceso científico derivada de las prácticas de libre distribución de conocimientos, hacen referencia de la Ciencia 2.0 o Ciencia Abierta, espacio donde se reconoce la utilización de herramientas de la denominada Web 2.0 (ARCILA-CALDERÓN, PIÑUEL-RAIGADA Y CALDERÍN-CRUZ, 2013).

Múltiples factores afectan de forma determinante. Por un lado, los nuevos soportes de acceso libre y gratuito, cuenta con el apoyo y beneplácito de grandes instituciones y entidades científico-académicas, que distinguen en esta nueva forma de publicar: calidad y aportación al conocimiento (CAPACCIONI, 2019).

En la misma línea, la Organización de las Naciones Unidas para la Educación, la Ciencia y la Cultura (UNESCO), - considerado el organismo internacional más importante en varios ámbitos - promueve la constitución de los modelos en AA como alternativa democrática y justa para la divulgación científica que define al movimiento 
Open Access como:

La posibilidad de acceder gratuita y universalmente a la información académica y de investigación revisada y aceptada por la comunidad científica - colegas- Se requiere que los titulares de los derechos de las obras publicadas en abierto concedan el derecho universal e irrevocable a copiar, usar, distribuir, transmitir y hacer trabajos derivados, en cualquier formato y para cualquier actividad lícita con la debida mención de autoría-. [...] Open Access utiliza las Tecnologías de la Información y la Comunicación (TIC) para aumentar y mejorar la difusión de las publicaciones [...] es para la UNESCO libertad, flexibilidad y equidad. (UNESCO, 2011, p. 1-2).

Es evidente que la digitalización está transformando perseverantemente la forma en que hacemos investigación, es decir, conceptos como acceso abierto, datos abiertos, ciencia 2.0, transparencia y colaboración, son considerablemente polemizados en la comunidad científica, en la política y en los medios de comunicación, donde la ciencia abierta se concibe como una evolución significativamente importante en el campo de la investigación; de forma tal, que la Ciencia 2.0 se deriva de la transformación digital, y se enfoca en las herramientas tecnológicas asociadas con este desarrollo, es decir, representa un movimiento ascendente dentro de la comunidad científica en este siglo (BERGHMANS, 2015).

En concordancia, Open Source Initiative promueve la libertad del software en la sociedad a través de la educación, la colaboración y la infraestructura; administrando la definición de código abierto ${ }^{1}$ y previniendo el abuso a los ideales éticos inherentes a esta corriente de pensamiento (OSI, 2019).

Para Spano, el Open Source y el Open Access son dos cauces que van en la misma dirección:

La sinergia entre ambas genera un sinfín de consecuencias positivas para los autores, las bibliotecas, las instituciones académicas y los usuarios finales, quienes, en definitiva, logran acceder a un universo de información científica sin otra restricción más que una conexión a Internet. En definitiva, tanto el acceso, como el código, como así también los estándares, tienen su punto común en un adjetivo: abiertos. Partiendo de esa base, cualquier persona podrá sentirse parte del universo digital. (SPANO, 2010, p. 10)

Como señala Ariño-Villarroya (2019) Open Source, Open Access y Open Science son denominaciones aprobadas para referirse a las ramas que defienden el acceso libre al software y al conocimiento científico. Cambios atomizados que han dado lugar a una variación de paradigma, que afecta por igual a la forma de entender el conocimiento científico, de generarlo, de acceder a él, y de reutilizarlo - siempre en beneficio del conjunto social. "A partir de conceptos iniciales como "ciencia cibernética", "infraestructura cibernética", "ciencia electrónica" o "E-research", el camino tomado nos llevó a la

1 La expresión Open Source (código abierto) empezó a utilizarse a finales de los años 90 del pasado siglo en referencia a cierto tipo de software informático. Se trataba en esencia de aquellos programas que ofrecieron a sus usuarios la posibilidad de modificación, alteración o adaptación del propio código fuente. De este modo, el programa podía evolucionar y mejorarse (OSI, 2019, p. 31). 
designación conocida hoy como Ciencia abierta / Open Science (QUINTANILHA, 2019, p. 203).

Entonces, cuando se habla de Open Science se piensa en Open Access, Open Data, Open Source y Open Notebook Science: "representa, en suma, un profundo cambio en la cultura científica vigente desde la llustración y, en especial, desde la explosión de las nuevas tecnologías en la última década del siglo XX" (MORA-MAS; GONZÁLEZSENMARTí, 2019, p. 2).

Estos cuatro titulares - Figura 1 - ejemplifican bien la situación actual del AA, como fórmula alternativa al tradicional pago por subscripción.

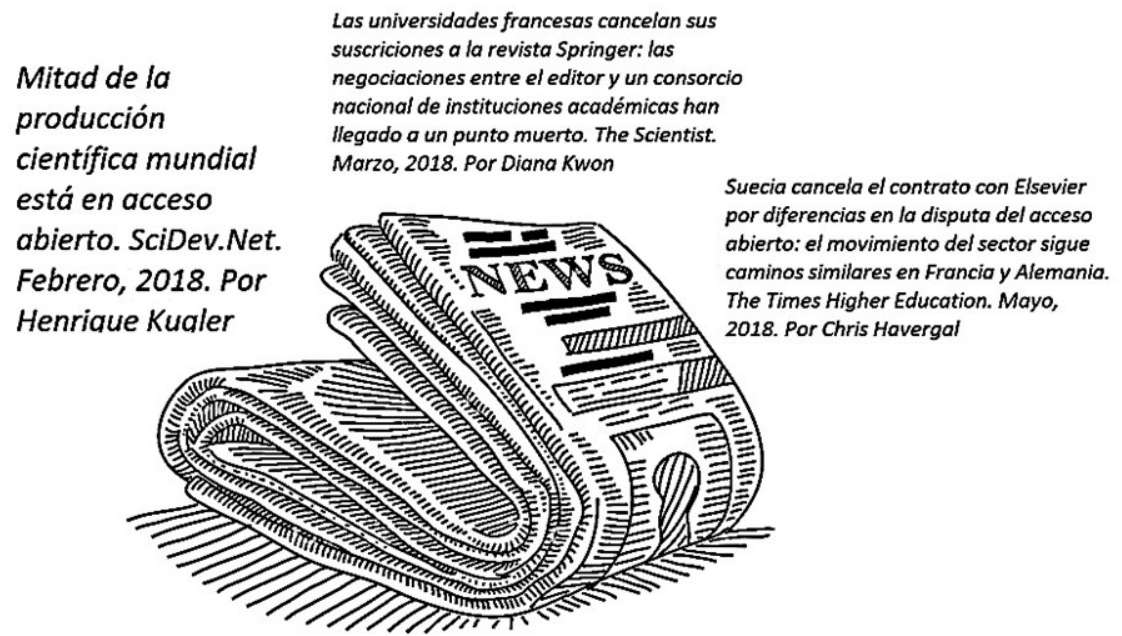

¿Adoptará el mundo el Plan S, la propuesta radical para exigir el acceso abierto a los documentos cientificos? Desde el lanzamiento en septiembre de 2018 del programa respaldado por Europa para exigir el acceso abierto (OA) inmediato a la literatura cientifica, 16 donantes en 13 países se han inscrito. Science. Enero, 2019. Por Tania Rabesandratana

Figura 1: Titulares en relación a iniciativas Open Access.

Fuente: elaboración propia.

No menos cierto es, que otro comienzo determinante del cambio, son las nuevas formas de medir la calidad de lo publicado y difundido, hay nuevas métricas. Como "El índice $\mathrm{H}$, que mide el número total de artículos de los que un científico es autor y el número de citas que esos documentos han recibido, puede ser más aceptable para algunos" (KUPIEC-WEGLINSKI, 2015 s. p). Prospectivamente, el modelo de ciencia abierta surge, como uno de los sucesos de mayor significancia en la transformación en la ciencia, y se posiciona gracias al acogimiento y resguardo de la producción científica de calidad, al proceso, movimiento y soporte en las plataformas de publicación y acceso al conocimiento e intercambio de datos (QUINTANILHA, 2019).

Con la necesidad seleccionar ante la creciente producción científica, y la consecuente escasez de recursos para financiar todas las propuestas, grupos de investigación e instituciones que están floreciendo, han convertido la evaluación, en un procedimiento cada vez más utilizado y valorado. No sin cuestionarse de qué manera se realiza este diagnóstico.

En este contexto y mundo cada vez más competitivo son muchos los autores 
http://periodicos.letras.ufmg.br/index.php/textolivre

Belo Horizonte, v. 12, n. 3, p. 144-167, set.-dez. 2019 - ISSN 1983-3652 DOI : $10.17851 / 1983-3652 \cdot 12 \cdot 3 \cdot 144-167$

críticos con un sistema de medición que prioriza (en mayor medida) lo "mundial" a lo "local-periférico" [...] No es de extrañar también que numerosos países (e.g: Japón) desarrollen iniciativas políticas destinadas a comercializar su ciencia académica, retrasando la publicación o publicando de forma incompleta para proteger el valor de sus hallazgos (patentes); situación que afecta adversamente a la ciencia abierta [...] (DUART; MENGUAL-ANDRÉS, 2014, p. 4-6).

En este momento coexisten dos criterios de evaluación, el más tradicional, la evaluación por pares - "... como fue el caso durante siglos, desde los albores de la escritura y la lectura" (MOUSTAFA, 2015, p. 142), que por subjetivo y difícil de estandarizar se ha compatibilizado e incluso sustituido por métodos matemáticos; y, los susodichos métodos cuantitativos que, aplicando fórmulas matemáticas, parecen poder sistematizar y objetivar el arbitraje.

Es este un punto vertebral. Citando inicialmente al Factor de Impacto (FI), cuyas ventajas son: la universalidad, el consenso internacional en su cálculo y aplicación; la sencillez de uso y comprensión; y la facilidad de comparación entre revistas de una misma área a nivel global (DÁVALOS-SOTELO, 2015), aunque otra perspectiva relevante, y no necesariamente en la misma dirección, articula que la discusión no sólo debe centrarse sobre si impacta o no los niveles de confianza para medir el conocimiento, sino también en la imperante necesidad de considerar un modelo más inclusivo que determine la productividad científica de los investigadores, no de las revistas, y que cuyos criterios certifiquen el conocimiento excluido de la opresión heredada por la reproducción de prácticas comerciales, pues lo anterior conlleva desfigurar la forma en que se visibiliza la ciencia, ya que cada disciplina tiene sus propias características por lo que comparar comunicación con matemáticas, no produce los mismos resultados (KUPIECWEGLINSKI, 2015; MOUSTAFA, 2015; QUINTANILHA \& CARDOSO, 2018). De hecho el $\mathrm{FI}$, no sólo es percibido como infructuoso o implícitamente dañino para la comunidad científica, también provee una distribución de citas sesgada (BOHANNON, 2016).

Cada vez de forma más ampliamente exacerbada, el Factor de Impacto presenta problemas para su aplicación, ya que beneficia a las revistas con pocos artículos y de gran extensión, así como aquellas que poseen un valor informativo inmediato; perjudica a las revistas y artículos clásicos, de revisión de la literatura y de tipo teórico-formativo; en consecuencia, el acceso a la información desvirtúa el resultado matemático, primando a revistas de países anglófonos, por el uso de la lengua inglesa y por su tradición en la edición científica, y a aquellas con temáticas controvertidas y/o globales; además, influye decididamente el tiempo y ritmo de citación, el cual es distinto en las diferentes áreas del conocimiento - por ejemplo, el periodo de cálculo de dos años sólo se puede utilizar en las áreas con una vertiginosa caducidad -; y la que en 2005 da lugar a la aparición de un indicador métrico alternativo, se destina para la evaluación de autoridades no teniendo en cuenta si sus artículos han sido citados o no (MIRÓ-ANDREU; BURBANO, 2013; MOUSTAFA, 2015).

Así pues, "en 2005, Jorge Hirsch, de la Universidad de California, ideaba el Índice H” (DÍAZ, 2014, p. 9). De acuerdo a Dávalos-Sotelo (2015), entre sus fortalezas destaca, estar diseñado específicamente para ponderar autoridades; es robusto, pues un aumento del número de artículos publicados por un autor no necesariamente tiene un efecto inmediato en el indicador; y permite valorar trayectorias y momentos puntuales en la literatura de un autor, así como la proyección a futuro. Aunque, exhibe debilidades ante 
coautorías y las redes clientelares de citación recíproca; perjudica al investigador novel con menos trabajos publicados, y al que prima la calidad frente a la cantidad; despliega problemas para diferenciar entre investigadores situados en niveles intermedios; no calcula las citas al documento, no teniendo en cuenta si son para enaltecer o para criticar su contenido; homonimias, variantes de firma, errores tipográficos y en general la falta de normalización, impresionan ineluctablemente al procesamiento de datos de este valor matemático (MIRÓ-ANDREU; BURBANO, 2013).

De lo anterior parte también uno de los últimos grandes cambios observados en la comunicación de la Ciencia: La redefinición del papel de investigador.

Del maremágnum de información que es posible encontrar hoy con cierta facilidad en la Red, la tarea del investigador gira hacia un rol más activo, encaminado a dar a conocer sus trabajos a través de perfiles y plataformas profesionales específicas.

La figura del investigador actual, está más próxima a la del comunicador proactivo y alfabetizado digitalmente que a la del científico clásico. El científico-investigador de hoy debe, además de escribir y difundir sus trabajos - lo que tradicionalmente era publicar, y que hoy esto es sólo una forma más de dar a conocer lo que se escribe -, lograr llegar al público. Un público que, saturado de información, necesita y quiere ser guiado. Tal como se explica en el trabajo titulado "El nuevo rol del investigador ante el posicionamiento del acceso abierto de la información científica", donde se expone la trasformación requerida actualmente por el investigador, ante el proceso de mediación con términos y conocimiento específicos, además del tiempo y cuidado invertido para unirse y mantenerse vigente ante las nuevas herramientas digitales que culminan en la creación de un currículum digital o perfil profesional que provee visibilidad a su producción científica en ámbitos internacionales (LÓPEZ-ORNELAS, 2019).

El autor de hoy debe saber cómo llegar a la gente que cree puede interesarle su obra, facilitándoles la información perfectamente estructurada, fácil de leer, transmitir y utilizar, para alcanzar el máximo número de citas posible - y eso aún no ha cambiado -, ganando en impacto y visibilidad entre sus colegas: "en esencia, el paradigma actual del reconocimiento de la ciencia está fundamentado, en la medida que aparezcan formando parte de las referencias bibliográficas de nuevas investigaciones." (MARTíNEZLARRARTE; DORTA-CONTRERAS, 2018, p. 2)

También la UNESCO ha destacado el hecho de que las oportunidades de Internet "no se limitan a los soportes de la comunicación, sino a los contenidos y a su forma de distribución y utilización" (RIAL-GARCíA, 2004, p. 2). Martínez-Rodríguez (2006) reconoce en la Red una dualidad, Internet es a la vez: una oportunidad de difusión mundial que, frente a las limitaciones de la cobertura informativa del saber científico en cualquiera de sus ramas, ha servido de puente entre la Ciencia y la Sociedad; y un medio de colaboración e interacción entre los individuos y sus pares que ha modificado las pautas de interacción social y el paradigma de la comunicación científica.

La marca personal y la gestión del perfil profesional ayudan al investigador como autor a fidelizar audiencias. Le dice al receptor: quién es el autor; sobre qué trabaja; con quién trabaja; cómo es la calidad de lo que publica y publicita; y dónde habitualmente deposita sus trabajos para poder, ahora o en el futuro, acceder a ellos.

El currículum digital y/o la gestión del perfil profesional aúnan dos intangibles: calidad y relevancia, que se alcanzaban a través de los titulares y editoriales en las que el 
autor publicaba.

La difusión no finaliza cuando el artículo es aceptado para ser publicado; a partir de ahí se abriría una nueva fase compartida por autor y revista como usuarios proactivos con interactividad online y acciones en red. En esta tarea de visibilizar la investigación difundida se identifican como acciones y/o herramientas tanto el envío del texto por correo electrónico a otros investigadores como la cesión del archivo en PDF (si se ha publicado en un sistema de acceso abierto) al repositorio de la Universidad. También es recomendable programar acciones de difusión con enlace al texto en las webs personales o de grupos de investigación y en las webs para encuentro de investigadores o para intercambio de artículos (desde PDF hasta vídeos) que operan como redes sociales de ámbitos profesionales o científicos como Academica.edu, Researchgate.net, [...] (TÚÑEZ LÓPEZ, 2014, p. 16-17).

Como se observa, las evidencias de cambio son factores determinantes del mismo, que motivan y explican las formulaciones hipotéticas que vertebrarán el presente artículo.

Recogiendo parte de la insondable comunidad científica como muestra, se formulan las siguientes hipótesis:

H1. Los investigadores españoles que publican en revistas de Comunicación indexadas en Scopus son proactivos digitales en redes sociales científicas.

H2. Los investigadores con un mayor número de publicaciones son más proactivos digitales en redes sociales científicas.

H3. Los investigadores más activos en redes sociales científicas tienen un Índice H más alto.

Como objetivo general y prioritario, en respuesta a la $\mathrm{H} 1$, inferir si a la luz de los cambios observados, los investigadores de hoy apuestan por formar parte activa del cambio o si por el contrario continúan apostando por un márquetin de terceros, aquel que pueda realizar el editor $u$ otros autores muy citados publicando en su misma cabecera.

En relación a la segunda y tercera hipótesis, se establece como objetivo general el poder aproximar al lector a la rentabilidad real, en términos de citación y visibilidad, que alcanzan los "Investigadores proactivos digitales" en redes sociales científicas, frente a los "Investigadores tradicionales", denominados así en adelante.

El "Investigador tradicional" - en esta investigación —, es aquel autor que no tiene perfil, o si lo tiene, no es activo en su gestión dando acceso a sus trabajos editoriales y congresuales, ni en la actualización de sus datos personales. Por contra, se denomina "Investigador proactivo digital", al autor que tiene y gestiona de forma activa su perfil en la Red, poniendo a disposición del público general sus trabajos y datos profesionales.

Objetivos específicos o colaterales a la investigación central: a) estudiar las tendencias hacia el acceso abierto a la investigación, en general en Scimago Journal \& Country Rank (SJR), en particular en Comunicación, por país, y por título; b) idiomas y predominios lingüísticos; c) procedencia geografía de las principales editoriales - aquellas que se sitúan en los primeros puestos del listado SJR -; d) el género en la muestra, la distribución hombre/mujer en términos absolutos y porcentuales; e) la actividad de los investigadores en las redes definidas para el estudio de la muestra, Academia.edu, Google Scholar, Open Researcher and Contributor ID (ORCID), y ResearchGate; f) procedencia laboral de los investigadores y condicionantes de la misma, si los hubiere; g) 
autores más y menos prolíficos, Media y Mediana de artículos publicados en el área estudiada - el área de Comunicación.

\section{Metodología de investigación}

Políticas públicas y organismos gubernamentales españoles acotan las fuentes de información de las que extraer los datos; así como la cronología de dicha recogida.

En esta investigación, el Universo atiende al conjunto de investigadores en activo que hayan publicado en revistas indexadas en Scimago Journal Rankings (SJR); la Población se conforma a partir de la unidad de segunda etapa, investigadores del área de Comunicación; y, de entre el Universo y la Población descritas, se establece una Muestra estratificada acotada a autores con nacionalidad española o afiliación a universidad española, que hayan publicado en el sexenio de investigación 2011 a 2016.

Como variable aleatoria, no controlada o de estudio, tener o no contar con presencia activa en la Red para la difusión de trabajos y la auto-gestión del perfil profesional. Esta variable es la que situará a los autores en "Investigadores tradicionales" o "Investigadores proactivos digitales".

La investigación que aquí se detalla, inicia con la revisión del sitio web de Scimago Journal Rank, un recurso validado por la Agencia Nacional de Evaluación de la Calidad y Acreditación (ANECA) a través de las convocatorias de la Comisión Nacional Evaluadora de la Actividad Investigadora (CNEAI), cuando en el Campo 7, referido a las Ciencias Sociales, Políticas, del Conocimiento y de Educación, valora preferentemente:

a) Los artículos publicados en revistas de reconocida valía, aceptándose como tales las incluidas en los listados por ámbitos científicos del «Journal Citation Reports (Social Sciences Edition)» y «Journal Citation Reports (Science Edition)» de la «Web of Science».

b) Asimismo (sin que necesariamente se valoren por igual), los artículos publicados en revistas situadas en posiciones relevantes de los listados de Scimago Journal Rank (SJR), y en «Arts and Humanities Citation Index» de la «Web of Science». (CNEAI, 2017, p. 11).

Algunos problemas exponenciales derivados de la metodología basada en Journal Citation Reports (JCR), es que JCR trabaja con el Factor de Impacto como indicador preferente, y éste no refleja el mérito personal de cada investigador. De hecho, extingue toda posible influencia positiva de una acción individual del autor, para visibilizar su trabajo, cuando asigna un número al conjunto de artículos publicados en la revista. Es decir, el FI vulnera algunas reglas básicas y éticas de la citación (MOUSTAFA, 2015). Otra razón, derivada de la problemática de esta medición, es que únicamente provee una instantánea de cuántos artículos publicados fueron citados en una revista en particular durante un período en particular, nada más (KAMPOURAKIS, 2018).

El procedimiento de investigación parte, por tanto, de la consulta del Scimago Journal Rank (SJR), para registrar los titulares que se adscriben al área de Comunicación entre los años 2011-2016 - el "sexenio de investigación" también es un término acuñado por la ANECA (2017) para la evaluación de los investigadores -, obteniendo así: a) un 
listado de publicaciones a vaciar para la conformación de la muestra; b) datos relacionados con la primera parte de los objetivos específicos marcados.

El vaciado, en biblioteconomía y documentación, consiste en tomar cada artículo como una unidad documental independiente $y$, en este caso, ese vaciado se materializa en la extracción de título, autor/es, páginas e idioma de cada artículo. Como resultado: un listado de artículos publicados en revistas listadas por SJR, en el sexenio de estudio 2011-2016, clasificadas en la base de datos como pertenecientes al área de Comunicación.

Para cribar este vaciado y obtener sólo autores españoles o con afiliación a universidad española, se acude a Scopus fuente principal de información durante toda la investigación - al inicio, tomando SJR como punto de partida para la realización del vaciado de artículos y autores; ahora, con la consulta y extracción de un catálogo de autoridades que confrontar en cada uno de los años vaciados; a término, como consecuencia de dar respuesta a la tercera formulación hipotética basada en la recuperación y comparación de índices $\mathrm{H}$-, obteniendo: primero, un listado de autores con afiliación española pertenecientes al campo de las Ciencias Sociales en las que se enmarca el área de Comunicación; finalmente, y a partir de la confrontación de esta lista con el vaciado, la relación de autores españoles, por nacionalidad o afiliación, que han publicado en el sexenio 2011-2016, y lo han hecho en revistas del área de Comunicación.

La base Scopus fue lanzada por la editorial Elsevier en 2004. [...] Se considera la base que tiene la mayor cobertura de resúmenes, citas y textos completos de la literatura científica internacional y brasileña. Además, fue pionera en la implementación del índice $\mathrm{h}$ como la herramienta bibliométrica de su base de datos. (SILVA \& CABRINI, 2017, p. 197-198). 


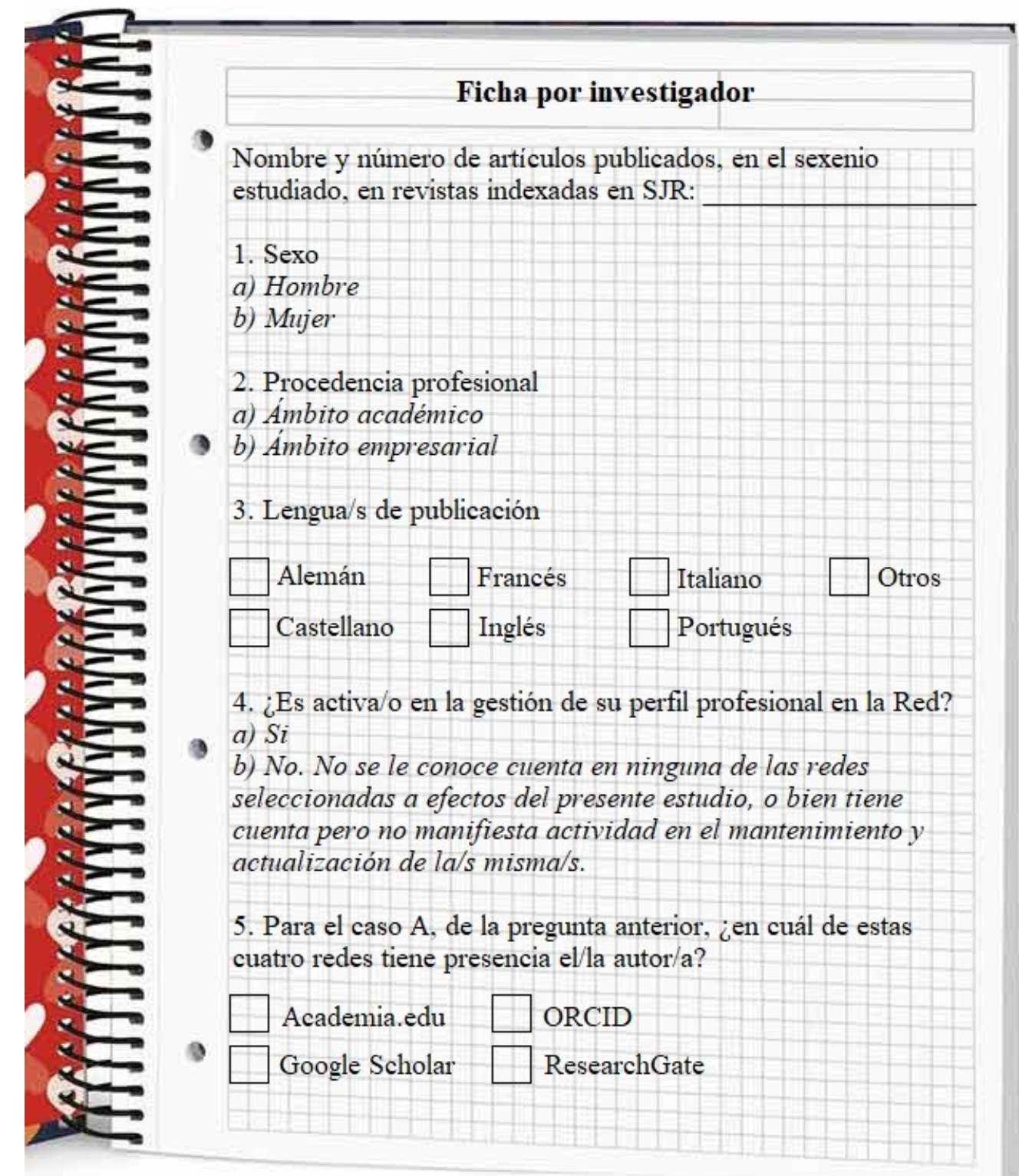

Figura 2: Ficha tipo, de aplicación a cada uno de los investigadores muestreados. Fuente: elaboración propia.

Paralelamente se diseña una ficha específica para aplicar al conjunto de autoridades de esta última lista - Figura 2 -, descartando las firmas simples que por su ambigüedad son de imposible distinción en Internet.

A término, y con una muestra final de 2,257 autores, una vez aplicada la ficha se consigue: a) dividir a los objetos de estudio en "Investigadores tradicionales" e "Investigadores proactivos digitales"; b) obtener más datos que permitan responder a los restantes objetivos específicos marcados al inicio de este artículo de investigación.

Para testar la presencia activa o no en la Red de los autores muestreados, se toman las herramientas web Academia.edu, Google Scholar, ORCID y ReserGate, como recursos de mayor visibilidad entre la comunidad científica para la gestión de perfiles 
profesionales de investigador en abierto (DELGADO-LÓPEZ-CÓZAR; ORDUÑA-MALEA, 2016); validando esta selección con los datos de tráfico observados por las herramientas de márquetin digital, Similar Web y ALEXIA.

ReserGate y Academia.edu, como redes sociales científicas al uso (ORTEGAPRIEGO, 2017); Google Scholar y ORCID, como sistemas de identificación de perfiles profesionales, susceptibles de facilitar la interconexión de los pares.

La primera hipótesis, $\mathrm{H} 1$, se responde con la diferencia matemática entre los perfiles "Investigador tradicional" e "Investigador proactivo digital", viendo cual es el mayoritario. Para responder a segunda y tercera, $\mathrm{H} 2$ y H3 , se hayan los autores prolíficos: para H2 los autores prolíficos del conjunto muestral, viendo a cuál de los dos perfiles "Investigador tradicional" e "Investigador proactivo digital" - pertenecen los autores con más publicaciones de la muestra; para H3, calculando los autores prolíficos de cada uno de los perfiles, tras lo cual se acude a las bases de datos de Scopus y, obteniendo los Índices $\mathrm{H}$ de esa selección de autores, se procede a la comparación del Índices H medio por perfil.

Se denomina autor prolífico a aquel investigador que se sitúe por encima de la Mediana de artículos definida. Esto es: en el caso de $\mathrm{H} 2$ los autores que superen los nueve artículos - la franja está entre 1 y 18 artículos publicados, el autor con más producción de esta muestra -; en el caso de H3, los "Investigador tradicional" serán prolíficos cuando superen los cuatro artículos y los "Investigadores proactivos digitales" lo serán cuando sobresalgan los nueve artículos.

En el campo de la estadística, la Mediana es el número que ocupa la posición central en una secuencia ordenada de datos. Su objetivo es resaltar el valor central de un orden jerárquico, a propósito de calcular el promedio de una asociación.

En telecomunicaciones e ingeniería informática, la "escalabilidad" es la propiedad deseable de un sistema, una red o un proceso, e indica su habilidad para reaccionar y adaptarse sin perder calidad, a entornos cambiantes. La metodología aplicada, revela esta propiedad en una doble dimensión: es escalable en el tiempo, pues es posible y de facto deseable que se repita este estudio para ver la actividad o no que observan los investigadores que ahora son y no son activos en la Red; y, es viable en el área de conocimiento a estudiar. El método puede ser replicado en cualquier otra área, y de hecho una comparativa, sería interesante para ver la actividad, o no, que manifiestan investigadores publicantes en titulares de otras áreas de conocimiento, diferentes a la aquí investigada, así como datos relacionados con los objetivos específicos planteados.

\section{Presentación y análisis de resultados}

Se verifica la primera hipótesis planteada, $\mathrm{H} 1$, tal como se muestra en la primera gráfica. Con 809 autores clasificados como inactivos, o lo que es lo mismo, un 36\% de "Investigadores tradicionales"; y 1,448 autores que manifiestan actividad en las redes seleccionadas para el estudio muestral - representado los "Investigadores proactivos digitales" un 64\% del total - (véase Gráfico 1), se puede afirmar que los investigadores españoles, que publican en revistas de Comunicación indexadas en SJR, son proactivos digitales en redes sociales científicas. El $87 \%$ tiene cuenta en al menos una; y el $61 \%$ es 
activo en su gestión.

Gráfico 1: Tipo de investigador según el comportamiento observado en la Red, gestionando activamente, o no, su perfil profesional en herramientas específicas.

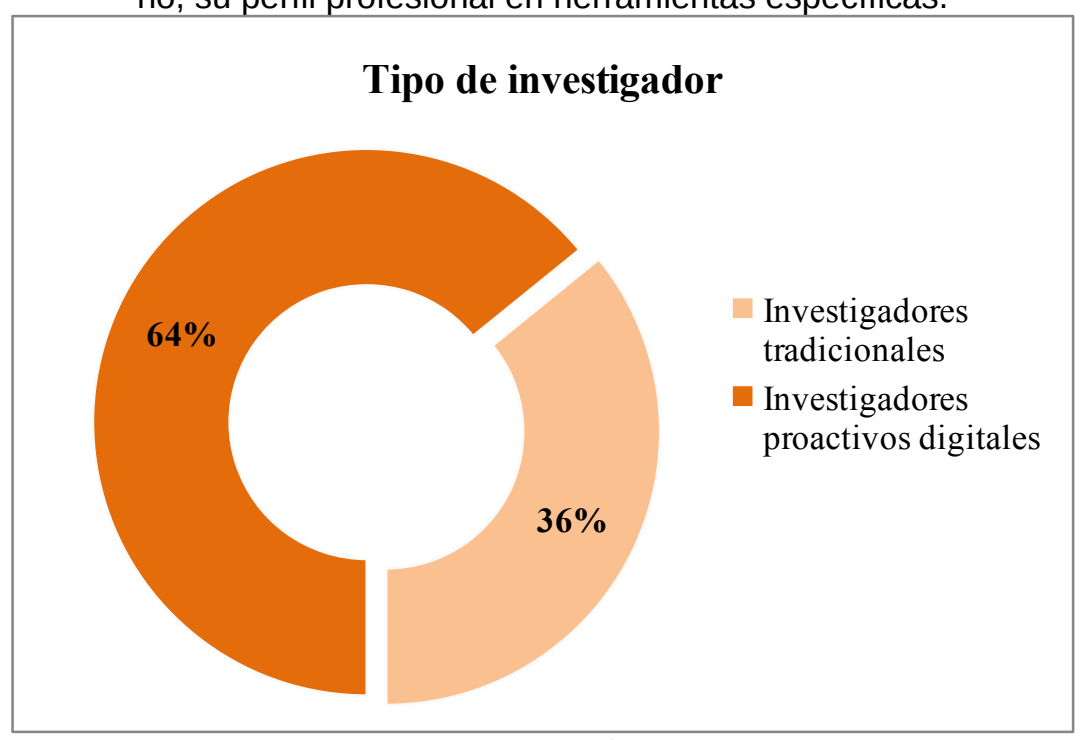

Fuente: elaboración propia.

Se verifica la segunda hipótesis, $\mathrm{H} 2$, los investigadores con un mayor número de publicaciones son más proactivos digitales en redes sociales científicas. Si tenemos presente que el número máximo de artículos publicados por los autores inactivos, o "Investigadores tradicionales" a efectos de esta investigación, se sitúa en siete; y que la Mediana de artículos publicados en el conjunto de la muestra se sitúa entre los nueve y los diez artículos; de este conjunto muestral, el cien por cien de autores prolíficos aquellos con nueve o más artículos - son "Investigadores proactivos digitales", o activos en redes sociales científicas gestionando su perfil y promocionando sus trabajos en ellas.

Se verifica la tercera hipótesis planteada, H3, los investigadores más activos en redes sociales científicas tienen un Índice $\mathrm{H}$ más alto - vinculado al cálculo aplicado ResearchGate y Google Scholar. De la sub-Muestra, autores prolíficos por perfil de investigador, la Media de Índices $\mathrm{H}$ en los "Investigadores tradicionales" se sitúa en dos, mientras que en los "Investigadores proactivos digitales" asciende a seis.

Como objetivo general y prioritario se establecía, a través de una parte de la insoldable comunidad científica, conocer el interés real de los investigadores por visibilizarse y visibilizar su trabajo en la Red: de los 2,257 autores-investigadores muestreados, solo un $13 \%$ carece de perfil en las redes seleccionadas; el $87 \%$ tiene cuenta en al menos una de ellas; y el $61 \%$ es activo en su gestión.

Los extremos. Se han detectado autores, los menos, con sitios web propios donde aportar al interesado una visión de $360^{\circ}$ sobre su trabajo y su persona, fidelizando audiencias. En contraposición, esos 125 autores que no pudieron ser estudiados por la ambigüedad de sus firmas - denotando un desconocimiento absoluto de las magnitudes de Internet -, por ejemplo, una de las principales funciones del Orcid, es precisamente homologar las firmas de los investigadores y autores del ámbito universitario, es decir, es un instrumento para obtener la identidad inequívoca (HERNÁNDEZ DE LA ROSA et al., 
2017).

De los autores que no tienen presencia en ninguna de las redes seleccionadas para el estudio de la muestra, el $69 \%$ son de procedencia profesional, o no vinculada directamente a la academia. Con esa misma variable, de procedencia profesional, son "Investigadores tradicionales" o inactivos en la Red el $86 \%$. Y es que existen terceros influyentes en la creación y mantenimiento de redes de gestión de perfiles en la comunidad investigadora, y todos ellos muy directamente relacionados con el mundo universitario. Primero, las entidades educativas de adscripción o pertenencia, que en las descripciones de su profesorado piden y dejan hueco a la inserción de este tipo de enlaces; segundo, los criterios de publicación de las propias titulares, que no solo dan cabida a la inserción de datos como el ORCID del investigador sino que no permiten enviar el documento a revisión si no se dispone del dato - tomado muchas veces estos sistemas de identificación web como herramientas de verificación y validación personal -; tercero, las entidades de evaluación, que al igual que las revistas y las Universidades, inicialmente dejaban espacio y hoy piden como obligatorio la inserción de estos elementos, que sólo si existe cuenta en determinadas redes de gestión de perfiles se pueden cubrir.

Objetivos colaterales a la investigación central. El acceso abierto al conocimiento.

En el conjunto de la base de datos de Scimago se observa una subida de casi cuatro puntos - 3,8 - entre 2011 y 2016. Inicia 2011 con el 13\% de titulares indexadas, cuyo modelo de negocio es el Open Access, y finaliza 2016 con el 17\%. En el área de Comunicación, los titulares en abierto se situaban en el $8 \%$ en 2011 ; y en casi en el once por ciento seis años más tarde, $11 \%$ en 2016 . Una subida de 3,3 puntos.

En Scimago Journal \& Country Rank las revistas en acceso abierto no sólo incrementan su presencia, sino que escalan posiciones respecto a años pretéritos. Caso de Francia, que no aportando ninguna en los años los previos, en 2015 y 2016 registra entorno al veinte por ciento de su producción en abierto. O España, donde en torno al treinta por ciento de sus publicaciones indexadas en Scimago Journal \& Country Rank, y clasificadas como de Comunicación, están en acceso abierto.

Brasil es un caso destacado por su aportación a la causa aperturista: desde el inicio del muestreo el cien por cien de su producción en SJR es en modelos Open Access.

El caso anglosajón, pesos pesados en la comunicación científica. De 197 títulos listados por Scimago Journal \& Country Rank en 2011, 80 de ellos eran publicados por editoriales británicas y 66 por editoriales estadounidenses, el $41 \%$ y el $34 \%$ respectivamente; en 2016, de los 256 títulos listados por Scimago Journal \& Country Rank, 102 de ellos los publicaban editoriales británicas y 73 estadounidenses, el $40 \%$ y el $29 \%$ respectivamente. En toda la serie se mantienen aproximados los porcentajes de participación de editoriales británicas y estadounidenses, aunando entre ambos países en torno al setenta por cien de la producción en el área estudiada. Con la particularidad de copar casi al cien por cien, año tras año, el top ten de publicaciones del área. Estos resultados, tampoco son un secreto, y mucho menos una sorpresa, ya que el idioma en que se escribe un documento científico, es determinante para ser citado,"...estas métricas terminan contribuyendo a factores de mayor impacto e influencia en revistas científicas que son principalmente de origen anglófono y controladas por los principales editoriales" (QUINTANILHA \& CARDOSO, 2018, p. 33). 
En Estados Unidos, las revistas listadas por SJR con un modelo de negocio OA no sobrepasan, ninguno de los seis años muestreados, el tres por cien; y en Gran Bretaña, siendo el primer país en aportar revistas al área estudiada, las publicaciones en abierto nunca llegan al dos por cien. Lo cual sucede, ya que las principales revistas en países angloparlantes, están supeditas por las principales editoriales que promueven un regreso a la publicación tradicional, centradas en los pagos.

De hecho, Gran Bretaña es el único caso que decrece el porcentaje de revistas Open Access, de los primeros años del estudio respecto a los últimos: $1,2 \%$ en acceso abierto en $2011 ; 1,2 \%$ del total, en acceso abierto, en $2012 ; 1,1 \%$ en $2013 ; 1,0$ en 2014 ; 1.0 en 2015; y un 0,98\% del total de revistas editadas en modelos OA, en 2016.

Visto por regiones, Latinoamérica frente a América del Norte. Aun cuando Estados Unidos es el segundo país en aportar titulares al área de Comunicación, el montante total de títulos en acceso abierto es inferior al de Latinoamérica, que en 2016 editaba el cien por cien de sus revistas de Comunicación, indexadas por SJR, en abierto.

En la línea del interés de Latinoamérica para con el acceso abierto, Costa y Leite (2019) publicaban recientemente un estudio centrado en el análisis y desarrollo de los repositorios institucionales como promotores del avance del acceso abierto en América Latina. Los autores concluían, que existe un amplio panorama de recursos de esta naturaleza, donde se ponen a disposición del público usuario una gran cantidad y naturaleza de documentos. "Entre las deficiencias de los sistemas, destacan la poca formalización del compromiso institucional y la baja presencia de políticas." (COSTA; LEITE, 2019, p. 12).

Europa combina modelos, tradición y vanguardia. Las regiones europeas parecen introducir la innovación de forma controlada y, como hemos visto en los titulares del apartado introductorio, casi obligada por los Gobiernos de los diferentes Estados comunitarios. Aquí algunos ejemplos:

Ciencia abierta, movimiento para hacer que la investigación científica, los datos y la difusión sean accesibles a todos los niveles de una sociedad inquisitiva. Avalado por FOSTER Plus (Fomento de la implementación práctica de Open Science en Horizon 2020 y más allá), proyecto de 2 años financiado por la Unión Europea (UE), y conciliado por 11 socios en seis países, cuyo principal objetivo, es contribuir a un cambio real y duradero en el comportamiento de los investigadores europeos para garantizar que Open Science (OS) se convierta en la norma.

Otro modelo es el primer informe de la Junta Ejecutiva del EOSC presenta las actividades que contribuirán a la implementación del EOSC, con líneas de acción y plazos para el período 2019-2020. Si bien este documento está destinado principalmente para que lo utilicen las partes interesadas involucradas en la construcción de EOSC, los documentos futuros se desarrollarán y se harán públicos para su uso por las comunidades de investigación, que serán los principales usuarios de las capacidades de EOSC.

Y no menos importante, es el Plan S es un buen ejemplo de ese esfuerzo por parte de Europa hacia el aperturismo del conocimiento científico (RABESANDRATANA, 2019). "La idea principal del Plan S es que a partir del 1 de enero de 2020 las publicaciones científicas que sean resultado de investigaciones que reciban ayudas procedentes de consejos de investigación y organismos de financiación nacionales y europeos, deben publicarse en revistas o plataformas de acceso abierto." (FRAGA-MEDÍN; BOJO- 


\title{
CANALES, 2019, p. 166)
}

Predominios lingüísticos - véase Gráfico 2. Con un abrumador $77,4 \%$ el castellano es la lengua mayoritariamente elegida para la publicación de 3,041 artículos, de un total de 3,928; seguida del inglés, que representa el 22\% del total, con 871 artículos escritos en este idioma. Sólo francés y portugués obtienen cifras que puedan ser consideradas, y aun así su porcentaje no alcanza el uno por cien.

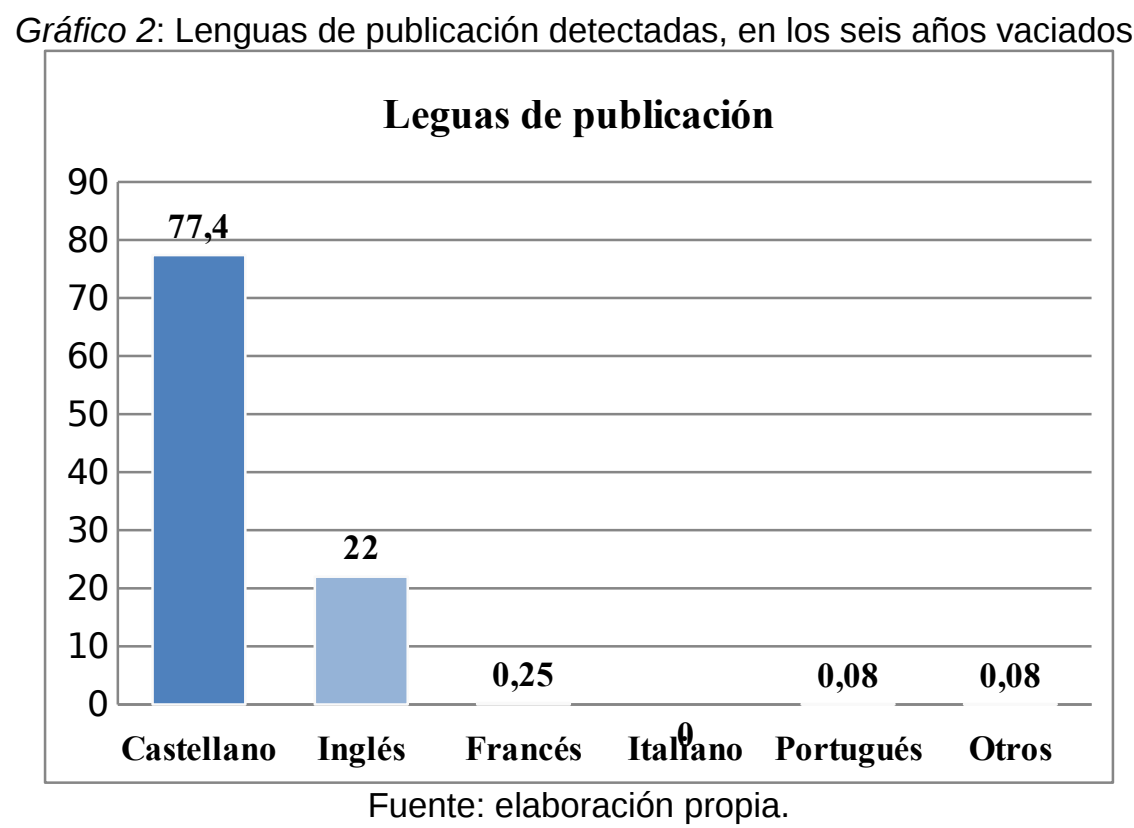

Coincidiendo estos resultados con otros estudios, como el de Galarraga-Aiestaran (2014) sobre lenguas minoritarias y divulgación científica, en su caso pormenorizando en la infrautilización, en periodismo y ciencia, del euskera - lengua propia del País Vasco francés, y las Comunidades Autónomas de País Vasco y Navarra en España.

\begin{abstract}
A partir de la Revolución Industrial, el inglés se ha constituido en el motor lingüístico del progreso científico y tecnológico para el imperio británico primero y, posteriormente, para los Estados Unidos, cuya infraestructura salió sin perjuicio de la Segunda Guerra Mundial. El español, en cambio, a lo largo de los siglos quedó al margen de las áreas donde se produjo el desarrollo científico, a pesar de haber sido la lengua de un gran imperio colonial, debido al rezago económico y tecnológico de su metrópoli. Esta situación de marginalidad sigue vigente, puesto que la mayoría de los hispanohablantes viven en países periféricos. (ERRICO, 2015, p. 225).
\end{abstract}

El género en la Muestra. Siendo más las autorías masculinas, con un $52,5 \%$ de hombres y un 47,4 \% de mujeres, vemos que los porcentajes entre las dos variables se distribuyen sin grandes diferencias, con una distancia de cinco puntos de los hombres respecto a las mujeres - equiparándose a otros estudios que, siendo previos, muestran una diferencia mayor entre las variables hombre/mujer, pero ya apuntando a una progresiva diminución del intervalo (URTEAGA-OLANO, 2010; TRACHANA, 2013; SOLSONA, 2015). 

muestra.

La actividad de los investigadores en las redes definidas para el estudio de la

Al igual que ResearchGate, Academia.edu presenta un crecimiento constante de perfiles $($ TCAC $=175 \%)$ y publicaciones $($ TCAC $=150 \%)$, siguiendo una tendencia lineal para ambas magnitudes desde 2012 (figura 2). Pero a partir de 2016 estos crecimientos experimentan una ligera ralentización. [...] estos resultados sugieren que Academia.edu está también perdiendo energía, experimentando una deceleración en su crecimiento. (ORTEGA-PRIEGO, 2018, p. 255-256).

Con casi un treinta y un por ciento de perfiles, ResearGate es la red, de las cuatro estudiadas, que más usuarios registra; seguida de cerca por Google Scholar y ORCID, respetivamente, con una distancia entre estas dos plataformas científicas de un punto.

Academia.edu, y a la distancia de algo más de trece puntos con respecto a la primera de grupo ResearGate, de siete con su competidor inmediato ORCID, se explica por el boicot que la comunidad investigadora ha realizado a un recurso que anunció grabar su empleo.

El último movimiento ha sucedido recientemente cuando Academia.edu ha introducido como un servicio premium $(7,42 €$ al mes) la posibilidad de poder hacer búsquedas avanzadas. Las búsquedas normales se hacen solo sobre el título del artículo con la opción premium también se buscará en el texto completo de los artículos. Esta estrategia va claramente en contra de la filosofía fundacional de ambas plataformas, pero ¿cómo reaccionará la comunidad científica? ¿penalizará a Academia.edu por "traicionar" la filosofía colaborativa entre autores que subyacía en su nacimiento o por el contrario valorarán de forma positiva una recuperación de documentos más potente? [...] Este paso de cobrar por un servicio premium es extraña porque el precio no aportará grandes beneficios económicos a Academia.edu, [...] aunque supongan un magnífico escaparate para difundir dicha producción. (CORTÉS, 2017, p. 1).

La procedencia laboral de los investigadores y los condicionantes de la misma: una presencia desigual en la Red y un notable descenso en el número de publicaciones científicas indexadas (véase Gráfico 3). 
Gráfico 3: Procedencia laboral actual del investigador publicante.

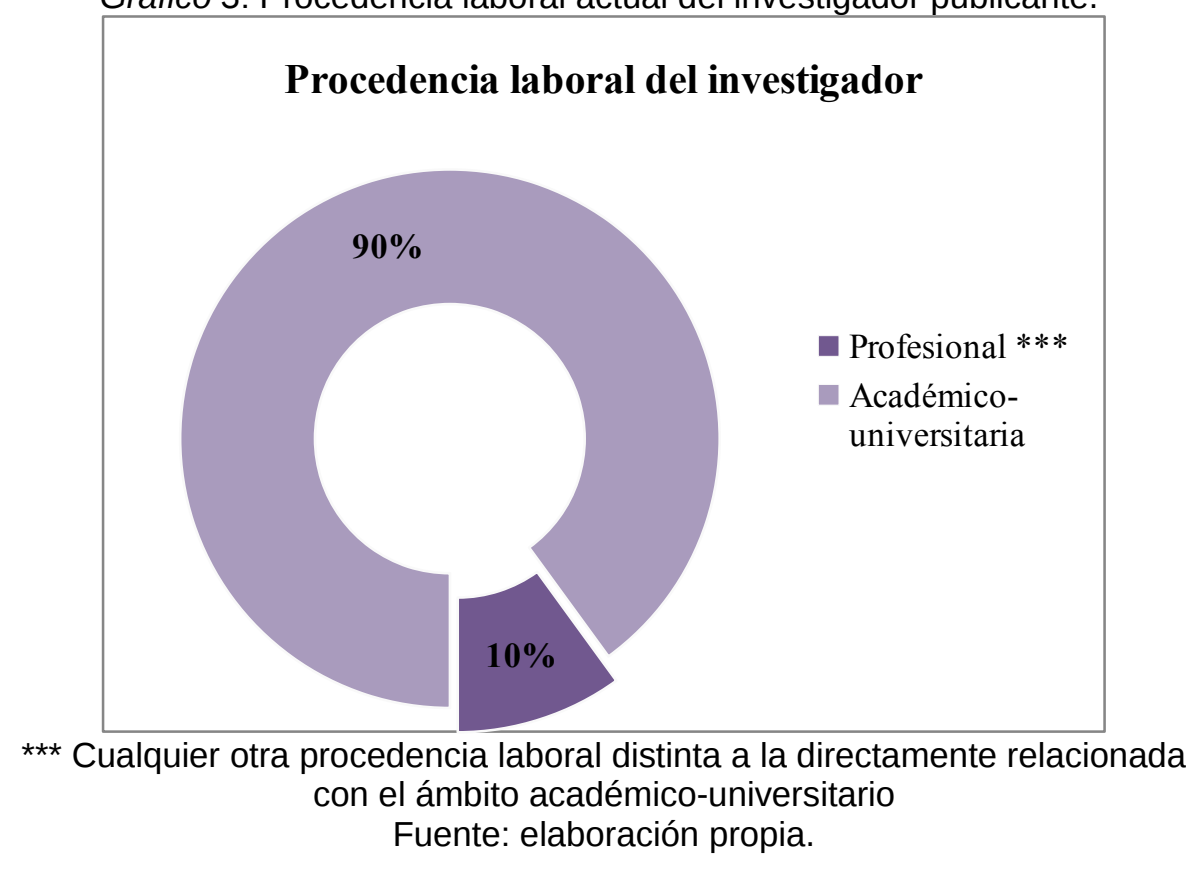

Definida la procedencia académica como la vinculación directa con la docencia y la investigación universitaria, y la procedencia profesional como todo lo demás: el $90 \%$ de los 2,257 autores muestreados pertenecen a la Academia - Gráfico 3. Casi el noventa por ciento de los autores de la Muestra están directamente vinculados al personal docenteinvestigador de la Universidad.

Los investigadores de la muestra cuya procedencia se hubo determinado profesional, o no vinculada directamente al ámbito académico-universitario, son los que de forma abrumadoramente mayoritaria carecen de entrada y/o emplean activamente estas herramientas de visibilización en la Red. De los de procedencia profesional: el 52\% no tiene perfil en ninguna de las redes vistas en esta investigación; y el 85\% se enmarcan en el perfil de autor inactivo, o "Investigador tradicional".

También su producción es menor. Los autores más prolíficos de procedencia profesional, lo son con cinco artículos cada uno; frente a sus colegas, los investigadores de procedencia académica, donde los más productivos los son con 18, 17, y 15 artículos cada uno.

Ocurre, además, que los dos casos de autores prolíficos en el ámbito de la procedencia profesional son muy especiales. No están directamente vinculados a la Universidad, pero si a la investigación, en una Agencia Estatal dedicada precisamente a dicha tarea. Son Elea Ruth Giménez Toledo e Isidro Francisco Aguillo Caño, investigadores del Consejo Superior de Investigaciones Científicas (CSIC); con estudios en Documentación, que indudablemente les ayudan también a la hora de sensibilizarles y facilitarles la tarea de estar informados - de mantenerse al día en las nuevas formas de divulgar y recuperar conocimiento científico. 


\section{Conclusiones}

Como se exponía en el apartado anterior de resultados, los investigadores españoles que publican en revistas de Comunicación indexadas en SJR, son proactivos digitales en redes sociales científicas; los investigadores con un mayor número de publicaciones, son más proactivos digitales en redes sociales científicas; y, los investigadores más activos digitales en redes sociales científicas, tienen un índice $\mathrm{H}$ más alto.

Los Investigadores proactivos en la Red triplican su rentabilidad - en términos de citación y visibilidad - sobre los que no lo son, mostrando también el interés del receptor por buscar y utilizar información que se encuentra en Internet.

Es posible presuponer una importancia futura a Internet como vehículo de divulgación científica. Tan posible a futuro, como palpable en el presente. Sólo un 13\% de los autores-investigadores muestreados carecen de perfil en las redes seleccionadas.

A reserva de la evolución observable en un futuro, se dibuja aquí una foto fija de una comunidad de investigadores que, concienciados del cambio, o auspiciados por terceros, apuestan en su importante mayoría por visibilizar su perfil investigador en la Red. Terceros influyentes - muy relacionados con el mundo de la Universidad -: la propia institución universitaria, las agencias de evaluación, y los titulares de publicación.

En cuanto a la alta presencia de investigadores de otras áreas en publicaciones del área de Comunicación, no son sino ejemplos palmarios de la interdisciplinariedad y la multidisciplinariedad existente en la Ciencia actual; así como muestra de la predisposición de los titulares por acercarse a los temas de interés, siendo más flexibles en la inclusión de un artículo si su potencial de cita es grande y toca colateralmente los temas principales de la publicación.

El acceso abierto a la información científica. El porcentaje de revistas Open Access se manifiesta al alza en toda la secuencia temporal. Incrementándose de forma exponencial, tanto la presencia, como la posición de los titulares en abierto.

El peso de la tradición. Gran Bretaña y Estado Unidos concentran el setenta por ciento de las revistas listadas por Scimago Journal \& Country Rank para el área de Comunicación, ocupando además, año tras año, las primeras posiciones de los listados. Su modelo de negocio está más que consolidado, y la necesidad de sumarse a la corriente aperturista es muy relativa. Sin embargo, sin ser cien por cien Open Access, muchos de estos reconocidos títulos han optado por fórmulas intermedias, guiños hacia la apertura parcial de su contenido, con modelos que premian la suscripción a la publicación pero facilitan información en abierto, de parte de sus trabajos (GALBÁN-RODRÍGUEZ, 2019) o tras periodos de embargo, adaptándose mínimamente a las exigencias sociales y gubernamentales actuales.

La lengua. Pese a que el setenta por ciento de las editoriales, como vemos, pertenecen a Estados Unidos y Gran Bretaña, ocupando, así mismo, éstas las primeras posiciones del ranking, los autores españoles o con vínculos con España apuestan por publicar, todavía en muy alta proporción, en castellano. Limitando inexorablemente el alcance de sus descubrimientos (GUERRERO-RAMOS, 2011).

Dividida la Muestra por géneros, la mayoría son autorías masculinas. Sin embargo, las proporciones entre las dos variables de género se distribuyen sin grandes diferencias, 
convendría seguir de cerca esta variable para ver si se produce el sorpasso, se agrandan las distancias, o se iguala la proporción.

Hay interés real en la mujer por visibilizarse en facetas de la sociedad históricamente reservadas a los hombres. Cifras de asistencia a eventos académicos como el IV Encuentro Internacional de Investigación de Género, así lo constatan (GUAZZARONI; PISSARELLO, 2016, p. 246).

Por último, las posibilidades de investigar y publicar, así como las de estar informado, son infinitamente mayores para los profesionales del sector universitario que para aquellos que provengan de cualquier otro ámbito laboral.

La investigación queda reservada, casi en exclusiva, para la Academia, entendida esta como el reducto de personas que directamente conforman el personal docente e investigador de la Universidad.

Los investigadores de la muestra cuya procedencia se hubo determinado profesional, o no vinculada directamente al ámbito universitario, son los que de forma abrumadoramente mayoritaria carecen de entrada y/o emplean activamente las herramientas de visibilización web.

\section{Implicaciones sociales, políticas y económicas de este estudio}

Implicaciones sociales.

Para la comunidad investigadora, es clara la necesidad de estar presente en Internet: hay un uso generalizado de la Red entre la comunidad científica, para visibilizarse y comunicarse con los pares; incrementan año a año el número de revistas de acceso abierto, escalando posiciones en los listados; la Sociedad demanda esta información, se entiende que la busca y la valora positivamente, porque la cita.

Para la Sociedad, dos reflexiones: a) queda demostrado que la voluntad mayoritaria hace que las cosas cambien; b) hoy es posible encontrar, en acceso abierto y gratuito, información de gran calidad depositada por los propios autores.

Implicaciones políticas.

Desde la educación deben diseñarse estrategias orientadas al efectivo uso de las nuevas tecnologías de la información y la comunicación, que pasan en gran medida por saber distinguir el grano de la paja - la información verdadera de la falsa; los contenidos de calidad de las aportaciones nulas -, en esa ventana a la igualdad de oportunidades que pretende ser el movimiento Open Access y el acceso a la información y la innovación científica.

Desde los organismos públicos encargados de la elaboración de políticas encaminadas a favorecer el progreso y las infraestructuras estratégicas, deben saber solventar la brecha entre personas, comunidades, y regiones, en el acceso a Internet.

Las entidades evaluadoras, a veces tapón para la innovación, que han limitado las fórmulas en abierto a jóvenes investigadores que están empezando y a investigadores consagrados, con sus sistemas y criterios de evaluación restrictivos, basados en rankings muy concretos y hasta cierto punto interesados en fomentar un contexto de copago para la propia rentabilidad, que se replanteen las fórmulas de valoración e incluso la 
formulación de más excepciones a la norma.

Implicaciones económicas.

Existe un nicho de mercado para la creación de spin-off encaminadas a ayudar al investigador en esta nueva tarea de visibilizarse y visibilizar su trabajo en la Red.

En la industria editorial, es clara la necesidad de virar cara nuevas formas de negocio que contemplen la apertura de, al menos, una parte de la información publicada. Gobiernos y Sociedad hacen presión para ello.

\section{Referencias}

ANECA, Agencia Nacional de Evaluación de la Calidad y Acreditación. CNEAl Comisión Nacional Evaluación de los tramos de investigación. 2017. Disponible: http://www.aneca.es . Consultado: 15 oct. 2019.

ARCILA-CALDERÓN, C.; PIÑUEL-RAIGADA, J.; CALDERÍN-CRUZ, M. The e-Research on Media \& Communications: Attitudes, Tools and Practices in Latin America Researchers. Comunicar: Revista científica iberoamericana de comunicación y educación, España, v. XX, n. 40, p. 111-118, 2013. Disponible: https://www.revistacomunicar.com/index.php? contenido=detalles\&numero=40\&articulo=40-2013-13. Consultado: 5 oct. 2019.

ARIÑO-VILLARROYA, A. Movilizaciones por la red. Las evoluciones del movimiento open. Arbor: ciencia, pensamiento y cultura, España, v. 195, n. 791, p. 1-15, 2019. Disponible: http://arbor.revistas.csic.es/index.php/arbor/article/view/2303/3307. Consultado: 1 oct. 2019.

BERGHMANS, S. The evolution of open science - how digitization is transforming research, 2015. Disponible: https://www.elsevier.com/connect/the-evolution-of-openscience-how-digitization-is-transforming-research. Consultado: 5 nov. 2019.

BOHANNON, J. Hate Journal Impact Factors? New Study Gives You One More Reason." Science Magazine, July $6, \quad 2016.2$ Disponible: http://www.sciencemag.org/news/2016/07/hatejournal-impact-factors-new-study-gives-youone-more-reason. Consultado: 10 nov. 2019.

CAPACCIONI, A. La monografia ad accesso aperto e gli sviluppi dell'Open Access. JLIS.it: Italian Journal of Library, Archives and Information Science. Rivista italiana di biblioteconomia, archivistica e scienza dell'informazione, Italia, v. 10, n. 1, p. 59-71, 2019. Disponible: https://dialnet.unirioja.es/servlet/articulo?codigo=6794166. Consultado: 15 oct. 2019.

CASTELLS, M. Comunicación y poder. Madrid, Alianza Editorial, 2009. 679 p. [ISBN: 97884-206-8499-4].

CNEAI, Comisión Nacional Evaluadora de la Actividad Investigadora. Resolución de 23 de noviembre de 2017, de la Comisión Nacional Evaluadora de la Actividad Investigadora, 
por la que se publican los criterios específicos aprobados para cada uno de los campos de evaluación. BOE, Agencia Estatal Boletín Oficial del Estado, España, 1 dic. 2017. Disponible: $\quad$ https://www.boe.es/boe/dias/2017/12/01/pdfs/BOE-A-2017-14085.pdf. Consultado: 1 oct. 2019.

CORTÉS, F. Servicios premium de pago ¿el fin de Academia.edu?. Loyola And News, Universidad Loyola Andalucía, 30 abr. 2017. Disponible: http://www.loyolaandnews.es/servicios-premium-de-pago-el-fin-de-academia-edu/. Consultado: 19 oct. 2019.

COSTA, M. ; LEITE, F. Open access institutional repositories in Latin America. Biblios: Revista electrónica de bibliotecología, archivología y museología, Brasil, n. 74, p. 1-14, 2019. Disponible: https://dialnet.unirioja.es/servlet/articulo?codigo $=7012683$. Consultado: 15 oct. 2019.

DÁVALOS-SOTELO, R. Sobre las formas de evaluación de las revistas científicas. Madera y bosques, México, v. 21, n. 3, p. 7-15, 2015. Disponible: https://dialnet.unirioja.es/servlet/articulo?codigo=5407786. Consultado: 11 oct. 2019.

DELGADO-LÓPEZ-CÓZAR, E., ORDUÑA-MALEA, E. ¿Cómo mejorar la difusión y visibilidad de un autor con Google Scholar Citations, ResearchGate y otras redes académicas? Construyendo la identidad digital de un científico en la web. Oviedo: Instituto de Ciencias de la Educación Universidad de Oviedo, 2016.

DÍAZ, G. El índice $\mathrm{H}$ : la forma objetiva de evaluar la producción científica de un investigador. Revista de la Facultad de Medicina Veterinaria y de Zootecnia, Colombia, v. 61, n. 2, p. 113-114, 2014. Disponible: https://dialnet.unirioja.es/servlet/articulo? codigo $=6573270$. Consultado: 10 oct. 2019.

DUART, J. M.; MENGUAL-ANDRÉS, S. Impacto de la Sociedad del Conocimiento en la universidad y en la comunicación científica. Relieve: Revista ELectrónica de Investigación y EValuación Educativa, España, v. 20, n. 2, p. 1-12, 2014. Disponible: https://www.uv.es/RELIEVE/v20n2/RELIEVEv20n2 M4.pdf. Consultado: 15 oct. 2019.

ERRICO, E. El español frente al inglés en la comunicación científico-académica: ¿una lengua que goza de buena salud?. Estudios de lingüística aplicada, México, n. 62, p. 223241, 2015. Disponible: https://ela.enallt.unam.mx/index.php/ela/issue/view/60. Consultado: 12 oct. 2019.

FOSTER. Open Science, 2019. Disponible: https://www.fosteropenscience.eu/fostertaxonomy/open-science. Consultado: 10 nov. 2019.

FRAGA-MEDÍN, C. A.; BOJO-CANALES, C. Acceso abierto, ciencia abierta y Plan S: su posible repercusión. Hospital a Domicilio HAD, España, v. 3, n. 2, p. 163-172, 2019. Disponible: https://revistahad.eu/index.php/revistahad/article/view/72/51. Consultado: 6 oct. 2019. 
GALARRAGA-AIESTARAN, A. Lenguas minoritarias y divulgación científica. 'El Huyar': periodismo y ciencia en euskera. MĖTODE Science Studies Journal, v. 80, n. 4, p. 177183, 2014. Disponible: $\quad$ https://ojs.uv.es/index.php/Metode/article/view/3077/3933. Consultado: 4 oct. 2019.

GALBÁN-RODRÍGUEZ, E. Preprints and preprint servers as academic communication tools. Revista Cubana de Información en Ciencias de la Salud, Cuba, v. 30, n. 1, p. 1-27, 2019. Disponible: http://www.acimed.sld.cu/index.php/acimed/article/view/1324/802. Consultado: 2 oct. 2019.

GUAZZARONI, V.; PISSARELLO, B. Cultura, sociedad y política en perspectiva de género. In: IV ENCUENTRO INTERNACIONAL DE INVESTIGACIÓN DE GÉNERO, 2016, Argentia, La Aljaba: Segunda Época, Revista de Estudios de la Mujer, Argentina: Universidad Nacional del Comahue/Universidad Nacional de La Pampa, 2016, p. 245-246. Disponible: https://dialnet.unirioja.es/ejemplar/468115. Consultado: 9 oct. 2019.

GUERRERO-RAMOS, G. La lengua de la ciencia y de la técnica. Uciencia: revista de divulgación científica de la Universidad de Málaga, España, n. 7, p. 50-51, 2011. Disponible: https://dialnet.unirioja.es/servlet/articulo?codigo=3689763. Consultado: 1 oct. 2019.

HERNÁNDEZ DE LA ROSA, Y. et al. Normalización de la identificación digital de un autor como registro único permanente: ORCID. CorSalud (Revista de Enfermedades Cardiovasculares), $\quad$ v. $\quad 9, \quad$ n. 2, p. 57-58, 2017. Disponible: https://www.medigraphic.com/pdfs/corsalud/cor-2017/cor172a.pdf. Consultado: 1 oct. 2019.

LÓPEZ-ORNELAS, M. El nuevo rol del investigador ante el posicionamiento del acceso abierto de la información científica. En: MORALES, K. F.; SANDOVAL, J. O.; LÓPEZORNELAS, M. (coord). Experiencias innovadoras educativas. México: Universidad Autónoma de Baja California. 2019. p. 15-32. Disponible: http://eprints.rclis.org/34196/. Consultado: 6 nov. 2019.

KAMPOURAKIS, K. What Is the Impact of the Impact Factor? p. 405-406. 2018. Disponible: $\quad$ https://link.springer.com/content/pdf/10.1007\%2Fs11191-018-9991-X.pdf. Consultado: 7 nov. 2019

KUPIEC-WEGLINSKI, J. Journal Impact Factor (JIF): The Good, the Bad, and the Ugly. Nowotwory. Journal of Oncology, v., 65, n., 6, $2015.481-482 . \quad$ DOI: 10.5603/NJO.2015.0094

MARTÍNEZ-LARRARTE, J. P.; DORTA-CONTRERAS, A. J. Ser citado o perecer. Revista Cubana de Reumatología: RCuR, Cuba, v. 20, n. 2, 2018. Disponible: http://www.revreumatologia.sld.cu/index.php/reumatologia/article/view/616. Consultado: 6 oct. 2019.

MARTÍNEZ-RODRÍGUEZ, A. Indicadores cibermétricos: ¿nuevas propuestas para medir 
la información en el entorno digital? ACIMED: Revista Cubana de Información en Ciencias de la Salud, Cuba, v. 14, n. 4, p. 1-20, 2006. Disponible: http://scielo.sld.cu/scielo.php? script=sci_arttext\&pid=S1024-94352006000400003. Consultado: 9 oct. 2019.

MIRÓ-ANDREU, O.; BURBANO, P. El factor de impacto, el índice $\mathrm{h}$ y otros indicadores bibliométricos. Anales del sistema sanitario de Navarra, España, v. 36, n. 3, p. 371-377, 2013. Disponible: https://recyt.fecyt.es//index.php/ASSN/article/view/24289/11854. Consultado: 14 oct. 2019.

MORA-MAS, F. J.; GONZÁLEZ-SENMARTÍ, A. CRUE universidades españolas ante el reto de la open science. RUIDERAe: Revista de Unidades de Información, España, n. 15, p. 1-10, 2019. Disponible: https://dialnet.unirioja.es/servlet/articulo?codigo=7061626. Consultado: 17 oct. 2019.

MOUSTAFA, K. The disaster of the impact factor. Science and engineering ethics, v. 21, n. 1, p. 139-142, 2015. Disponible: https://link.springer.com/article/10.1007/s11948-0149517-0. Consultado: 8 nov. 2019.

OSI, Open Source Initiative. History of the OSI. 2019. Disponible: https://opensource.org/history. Consultado: 14 oct. 2019.

ORTEGA-PRIEGO, J. Lo que los datos esconden: evolución de las redes sociales académicas. Anuario ThinkEPI, España, v. 12, n. 1, p. 254-257, 2018. Disponible: https://recyt.fecyt.es/index.php/ThinkEPI/article/view/thinkepi.2018.38/39156. Consultado: 12 oct. 2019.

ORTEGA-PRIEGO, J. Redes sociales académicas ¿espacios colaborativos o clubes Diógenes?. Anuario ThinkEPI, España, v. 11, n. 1, p. 225-229, 2017. Disponible: https://recyt.fecyt.es/index.php/ThinkEPI/article/view/thinkepi.2017.42/35526. Consultado: 15 oct. 2019.

QUINTANILHA, T. Os quatro grandes desafios ao modelo de Ciência Aberta:(des) acreditação, informalidade, comodificação e predação. Texto Livre: Linguagem e Tecnologia, 12(2), 202-213, 2019.2 Disponible: http://www.periodicos.letras.ufmg.br/index.php/textolivre/article/view/15146/1125612565. Consultado: 5 nov. 2019.

QUINTANILHA, T.; CARDOSO, G. The impact factor as a legitimator of the scientific knowledge produced: a review of the literature. JANUS.NET e-journal of International Relations, $\quad$ v. $\quad 9, \quad$ n. $2, \quad$ p. $32-44, \quad 2018 . \quad$ Disponible: http://repositorio.ual.pt/bitstream/11144/3909/3/EN_JANUS.NET_VOL9N2_art03.pdf. Consultado: 6 nov. 2019.

RABESANDRATANA, T. Will the world embrace Plan S, the radical proposal to mandate open access to science papers?. Science, 03 ene. 2019. Disponible: https://www.sciencemag.org/news/2019/01/will-world-embrace-plan-s-radical-proposalmandate-open-access-science-papers. Consultado: 5 oct. 2019. 
RIAL-GARCÍA, A. El papel de los portales de internet de las universidades españolas en la divulgación del conocimiento científico-tecnológico. Quark: Ciencia, medicina, comunicación y cultura, España, n. 33, p. 77-90, 2004. Disponible: https://dialnet.unirioja.es/servlet/articulo?codigo=1064357. Consultado: 1 oct. 2019.

SILVA, D.; CABRINI-GRACIO, M. Índice h de Hirsch: análise comparativa entre as bases de dados Scopus, Web of Science e Google Acadêmico. Em Questão, Brasil, v. 23, n. Extra 5, p. 196-212, 2017. Disponible: https://dialnet.unirioja.es/servlet/articulo? codigo $=6134792$. Consultado: 19 oct. 2019.

SOLSONA, N. Los saberes científicos de las mujeres en el currículum. Qurriculum: Revista de Teoría, Investigación y Práctica Educativa, España, n. 28, p. 32-54, 2015. Disponible: https://dialnet.unirioja.es/servlet/articulo?codigo=5031694. Consultado: 22 oct. 2019.

SPANO, D. El Open Source como facilitador del Open Access. In: II ENCUENTRO IBEROAMERICANO DE EDITORES CIENTÍFICOS, 2010. Buenos Aires: Caicyt, 2010. p. 1-12. Disponible: https://dialnet.unirioja.es/servlet/articulo?codigo=3342024. Consultado: 23 oct. 2019.

TRACHANA, A. Espacio y género. Ángulo Recto: Revista de estudios sobre la ciudad como espacio plural, España, v. 5, n. 1, p. 117-131, 2013. Disponible: https://revistas.ucm.es/index.php/ANRE/article/view/42071/40046. Consultado: 22 oct. 2019.

TÚÑEZ LÓPEZ, J. M. Perfiles de Comunicación en Google Scholar Metrics, índice h y nuevas estrategias de difusión de la investigación. Historia y comunicación social, España, v. 19, n. Extra 3, p. 15-25, 2014. Disponible: https://minerva.usc.es/xmlui/handle/10347/18771. Consultado: 10 oct. 2019.

UNESCO, United Nations Educational, Scientific and Cultural Organization. Open Access Forum 2011: UNESCO to host expert meeting. 2011. Disponible: http://www.unesco.org/new/en/brasilia/about-this-office/single-

view/news/open_access_forum_2011_unesco to host_expert meeting/. Consultado: 26 oct. 2019.

URTEAGA-OLANO, E. Ciencia y género. Clepsydra: Revista de Estudios de Género y Teoría Feminista, España, n. 9, p. 121-132, 2010. Disponible: http//s:dialnet.unirioja.es/servlet/articulo?codigo=3368739. Consultado: 28 oct. 2019.

Recebido em dia 17 de outubro de 2019. Aprovado em dia 03 de novembro de 2019. 